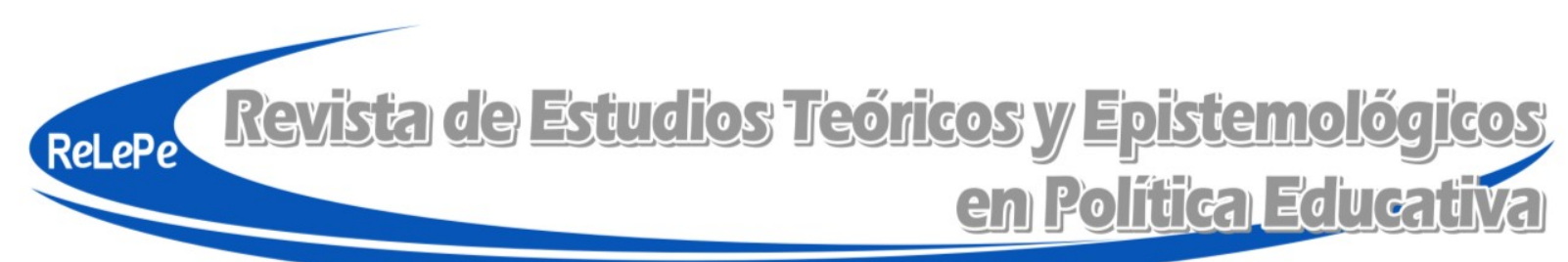

ISSN 2409-3696

DOI: $10.5212 /$ retepe.v.4.020

\title{
O caráter histórico da pesquisa em educação
}

\author{
Olinda Evangelista \\ Universidade do Oeste Catarinense \\ Universidade Federal de Santa Catarina \\ olindaevangelista35@hotmail.com \\ http://orcid.org/000-0001-5360-2521 \\ Eneida Shiroma \\ Universidade Federal de Santa Catarina \\ eneidashiroma@gmail.com \\ http://orcid.org/0000-0002-0506-7058
}

Resumo: Este artigo tem por objetivo discutir aspectos da pesquisa em educação no Brasil, particularmente sobre a importância da dimensão histórica nos estudos de políticas para a educação. Refletir sobre o caráter histórico da pesquisa educacional remete à necessidade de conhecerem-se as formas de determinação históricas, derivadas das relações sociais que configuram a própria existência humana. Problematizar a produção de conhecimento requer considerar que o objeto de estudo, o sujeito pesquisador, teoria e método são produzidos historicamente em meio a relações sociais concretas. $\mathrm{O}$ trabalho com categorias do materialismo histórico - totalidade, contradição, mediação, hegemonia, reprodução, classe social, capital, trabalho - contribui para a apropriação das conexões íntimas que dão sentido à empiria, às relações e às correlações de forças sociais que a determinam. Essa perspectiva teórico-metodológica oferece ferramentas importantes para a compreensão das políticas educacionais no Brasil de hoje e do papel histórico da educação na produção, na reprodução e na contestação das relações sociais de produção.

Palavras-chave: Pesquisa em Educação. Brasil - 2000-2019. História. Política Educacional.

\section{The historical character of research in education}

\begin{abstract}
This paper aims at discussing aspects of the educational research in Brazil, mainly the relevance of the historical dimension for the studies policies for education. Reflecting on the historical character of educational research refers to the need to know the ways in which the forms of historical determination, derived from social relations that configure the human existence. Inquiring the processes of knowledge production requires to consider that the research object, the researcher him/herself, theory and method are all historically produced within concrete social relations. The work with categories of the historical materialism - totality, contradiction, mediation, hegemony, reproduction, social class, capital, labor contribute to the appropriation of the central nexus that give meaning to the empirical research, to the relations and social forces correlations that determine the object of study. This theoretical and methodological perspective provide important tools for the study of the current policy education in Brazil and of the historical role of education in production, reproduction and contestation of social relations of production.
\end{abstract}

Keywords: Education Research. Brazil - 2000-2019. History. Education policy. 


\section{El carácter histórico de la investigación en educación}

Resumen: El artículo tiene como objetivo discutir aspectos de la investigación educativa en Brasil, particularmente sobre la importancia de la dimensión histórica en los estudios de políticas para la educación. Reflexionar sobre el carácter histórico de la investigación educativa señala la necesidad de conocer las formas de determinación histórica derivadas de las relaciones sociales, que configuran la propia existencia humana. Problematizar la producción de conocimiento requiere considerar que el objeto de estudio, el sujeto investigador, teoría y método son producidos históricamente en medio de relaciones sociales concretas. El trabajo con categorías del materialismo histórico (totalidad, contradicción, mediación, hegemonía, reproducción, clase social, capital, trabajo) contribuye para apropiarse de las conexiones íntimas que dan sentido a la empiria, a las relaciones y a las correlaciones de las fuerzas sociales que la determinan. Esta perspectiva teórico-metodológica ofrece herramientas importantes para la comprensión de las políticas educativas en el Brasil de hoy y del papel histórico de la educación en la producción, en la reproducción y en la contestación de las relaciones sociales de producción.

Palabras-clave: Pesquisa en Educación. Brasil - 2000-2019. Historia. Política Educativa.

\section{Introdução}

Diego não conbecia o mar. O pai, Santiago Kovadloff, levou-o para que descobrisse o mar. Viajaram para o Sul. Ele, o mar, estava do outro lado das dunas altas, esperando. Quando o menino e o pai enfim alcançaram aquelas alturas de areia, depois de muito caminhar, o mar estava na frente de seus olhos. E foi tanta a imensidão do mar, e tanto fulgor, que o menino ficou mudo de beleza. E quando finalmente conseguiu falar, tremendo, gaguejando, pediu ao pai:

A epígrafe de Galeano oferece, de modo aparentemente singelo, um instigante âmbito de reflexão sobre questões relativas à produção e à difusão do conhecimento científico, mormente no que se refere ao seu aspecto histórico e social. Por pensarmos na esteira de outros, a possibilidade de conhecer o legado do pensamento humano e compreender sua construção histórica e coletiva está posta. Podemos nos apropriar do conhecimento acumulado pela humanidade acerca de sua existência como natureza e como cultura e, certamente, tal processo nos interpela - a nós pesquisadores - diretamente, pois produzimos e difundimos conhecimento. Em nosso trabalho cotidiano, ensinamos a olhar, e de muitas maneiras. Algumas delas discutiremos aqui com a expectativa de contribuir para o debate acerca de uma atividade humana essencialmente educativa, segundo a perspectiva de Mészáros (2010).

De nosso ponto de vista, entre os movimentos de fecundação do conhecimento e de abertura de novas searas de pensamento, estão ver e colocar questões sobre os dados da realidade, as relações, as práticas, os conflitos, as ideias, os fenômenos, os fatos: em uma palavra, a exemplo de Ianni (2011), cabe-nos pensar sobre o "todo vivo" no qual estamos mergulhados. No caso da Educação, essa é a empiria que nos diz respeito e sendo sensíveis a ela encetamos diálogos em múltiplas direções. O diálogo com a empiria - ou a prática social - emerge como fundamental, pois, de acordo com Thompson (1981, p. 49), sem "engajamento empírico não há teoria".

Um segundo diálogo precisa ser feito com as explicações que encontramos sobre os fenômenos sobre os quais nos debruçamos - não aquelas próprias do senso comum ou mesmo do bom senso, mas aquelas que de alguma forma submeteram esses fenômenos ao escrutínio e se formalizaram por meio de pesquisas acadêmicas. Por seu intermédio, acedemos a essa forma de saber acumulado, o que nos permite realizar estudos sobre um tema; verificar o que dele é sabido; identificar as polêmicas que o cercam; perceber as lacunas a preencher; se há novas formas de se pensar sobre ele. Se esse procedimento podemos denominar formalmente de revisão bibliográfica 
ou balanço de literatura, ele é mais do que isso, pois se trata de um diálogo fecundo com as explicações oferecidas ao mesmo fenômeno.

Ianni (2011, p. 401) refere Marx, afirmando que, além de ser crítico ao objeto, em um primeiro nível, em um segundo seu pensamento "[...] implica sempre na crítica das explicações prevalecentes sobre o mesmo fato". Pesquisadores que se propõem a agregar uma contribuição à sua área procuram, sobre os ombros de gigantes, ver mais longe, ampliar seu campo de visão. É assim que autores clássicos, pesquisadores críticos, nos ajudam a ver, a pensar, a conhecer. Thompson (1981, p. 69) assinala que “[...] qualquer momento histórico é ao mesmo tempo resultado de processos anteriores e um índice da direção de seu fluxo futuro". É possível derivar, pois, que cada conhecimento produzido "[...] é um momento do ser, mas também um momento do vir-a-ser" (THOMPSON, 1981, p. 69, grifos do autor). Como na alegoria de Galeano, acompanhados de outros pesquisadores - do alto das dunas -, em outras palavras, do conhecimento socialmente produzido, conseguimos maior visão da totalidade. Olhando para o tempo passado, reconhecemos o que foi construído; para o futuro, vislumbramos as tendências e as tarefas de conceptualização que talvez nos caibam. Para Ianni (2011),

[...] em todos os momentos, está em questão esse andamento da reflexão dialética. Eu acrescentaria "presente passado", "passado presente". Porque toda a reflexão sobre a realidade social resgata o aqui, o agora e o antes, e o daqui a pouco. É o pretérito imediato num longínquo. E sempre naquela acepção de que o passado não é o passado que está na cronologia. É o passado que é responsável pela constituição deste presente e este presente não é cronologia. Ele tem a ver com a cronologia. Mas a cronologia é só um gancho para se conhecer o presente. (IANNI, 2011, p. 399-340).

É na história, portanto, que captamos o sentido do nosso trabalho, e dos alheios, de produção e de difusão do saber, fundamental para que possamos conhecer a realidade e transformá-la. Afinal, é a análise crítica do existente que pode revelar os possíveis futuros que ele encerra (MORAES, 2009).

A empreitada da pesquisa supõe, então, uma vasta incursão sobre o que foi produzido acerca de um tema. Algumas indagações são necessárias: como se constituiu o tema de estudo para os autores em exame? Quais as questões colocadas pelos que o pesquisaram? Que embates o geraram ou dele nasceram? Que abordagens foram feitas e quais seus avanços e limites? Quais conceitos lhe deram sustentação? Que categorias foram utilizadas para interpretá-lo? Quais são os discursos sobre ele construídos e qual é hegemônico? Suas determinações foram compreendidas? Entre tantas questões, a interlocução com outros pesquisadores que investigam o mesmo tema de pesquisa confirma ser necessária. A pesquisa científica constrói-se, também, sobre o legado das anteriores e na interlocução com elas. Ignorar a produção acumulada social e historicamente significaria negligenciar o conhecimento científico anterior, empobrecendo o trabalho intelectivo, além de frear um avanço para a área de pesquisa. Dois problemas decorrem desse posicionamento. De um lado, incorre-se na negação da ciência; e, de outro, no abandono da tarefa, indicada por Thompson (1981), de conhecer nossa própria história, de saber de onde viemos e como nossa humanidade foi produzida.

O percurso analítico que sistematizamos a seguir, em três eixos, tem em vista contribuir para responder parte das questões levantadas e refletir sobre a importância da pesquisa em educação e sua dimensão histórica. 


\section{Primeiro eixo: o caráter histórico da pesquisa educacional}

O primeiro problema com o qual nos defrontamos ao tratarmos da pesquisa educacional refere-se ao seu caráter histórico, e de fato ele é central. Não está em questão a citação de fatos históricos, datações, localizações ou nomeação de sujeitos importantes ou não. Embora esses dados componham a historicidade do tema de estudo, são insuficientes para caracterizar uma pesquisa como histórica.

Críticos das abordagens pós-modernas mostram seus limites ao descartarem precisamente a historicidade na qual seus objetos de estudo foram gestados e estão mergulhados ${ }^{1}$. A crítica aos pesquisadores marxistas taxa-os de deterministas, economicistas e reducionistas. Não nos interessa, neste momento, retomar esse debate ${ }^{2}$, mas refletir sobre o nosso próprio argumento para ver o quanto lidamos com ele e o quanto possui de capacidade explicativa.

A pergunta preliminar que orienta esse eixo é: o que atribui historicidade a um estudo? Poderíamos responder com o óbvio: o fato de que o real que lhe confere sentido é histórico. Contudo, a obviedade é aparente. Não é demais lembrarmos que, a partir dos anos de 1990, teorias que davam a história por encerrada (FUKUYAMA, 1992) proliferaram e entraram na universidade impactando diretamente o ensino e a produção de conhecimento. Delas derivaram questionamentos sobre a possibilidade do conhecimento objetivo do real, do social, promovendo, em contraposição, concepções relativistas. Distantes dessa especulação, nosso pressuposto é de que o real e o social existem, têm história e são cognoscíveis nas suas determinações - embora não imediata, nem totalmente. Com Netto (2003, p. 13), entendemos que "[...] o social tem uma dimensão simbólica, porque sem símbolo não há vida social; mas a vida social é irredutível à sua simbologia, ela tem uma efetividade, uma positividade, ela tem uma objetividade que não pode ser suprimida". O caráter histórico de nossa existência é ressaltado por Marx (1978, p. 41) nos Manuscritos econômico-filosóficos de 1844: "E como tudo que é natural deve nascer, assim também o homem possui seu ato de nascimento: a história, que, no entanto, é para ele uma história consciente, e que, portanto, como ato de nascimento acompanhado de consciência é ato de nascimento que se supera".

Há nessa passagem três importantes ideias: o homem nasce na história; o homem nasce com consciência, isto é, capaz de pensar; o homem nasce capaz de transformar sua existência se compreendê-la. Gramsci (1966) avigora essa abordagem quando afirma que o ser humano nasce socialmente e não lhe é possível escapar a essa determinação original. Nascer socialmente significa não apenas nascer na história, mas nascer em um dado momento dessa história e em uma dada inserção social, com pertencimento de classe. O fato do nascimento sócio-histórico imprime uma dada possibilidade de consciência, mas não inexorável. Nascer com capacidade de

\footnotetext{
${ }^{1}$ Citamos dois autores que discutem o tema. Para Iasi (2017, p. 30): "O capitalismo mudou para uma sociedade pósindustrial; o trabalho, e consequentemente, as classes e a luta de classes perderam a centralidade, a utopia socialista foi substituída pelo aperfeiçoamento da ordem liberal democrática; e, finalmente, as certezas de uma racionalidade moderna e suas expressões filosóficas, científicas, artísticas, religiosas e outras, foram substituídas por um complexo jogo de linguagem e discursos que perderam a capacidade de se legitimar além de seu campo específico de legalidade própria, conformando um quadro cultural fundado no acaso, na incerteza, no fragmentário, no acidental, no fortuito: a modernidade foi superada pela pós-modernidade". Montaño (2014, p. 23, grifos do autor) assim se pronuncia: "Uma racionalidade hiper-desarticuladora e fragmentada da totalidade social - seja pela razão formal-abstrata: positivismo, neopositivismo, sistemismo etc., seja pela chamada razão pós-moderna -, com a imposição de um linguajar que ideologicamente leve a uma forma fetichizada e reificada de visão da realidade, ocultando o verdadeiro sentido das reformas [derivadas do neoliberalismo] e mostrando-se como "vontade popular".

${ }^{2}$ Esse tema foi profundamente discutido no âmbito internacional por Ellen Wood (1996), David Harvey (1992), Perry Anderson (1992), Terry Eagleton (1997) e, no Brasil, por Maria Celia M. de Moraes (2004), Mario Duayer (2016), entre outros. Valentini (2018), em sua pesquisa sobre ações afirmativas, assinala que o pensamento pósmoderno se configura como expressão ideológica da atual forma assumida pelo capitalismo, especialmente porque colabora para obscurecer as determinações históricas.
} 
pensar não é mera abstração, mas um fato também histórico, determinado pela mediação do tipo de sociedade vigente, isto é, mediado pelas relações sociais de produção e pela cultura daquele momento histórico, considerando quem tem acesso ao conhecimento e aos bens culturais que possibilitem pensar-se e pensar o mundo.

Admitir que o ser humano é determinado historicamente não corresponde a um aprisionamento em camisa de força ou a uma determinação mecânica de sua existência. Não nascemos pré-determinados, nem enclausurados em um pensamento dado, mas no âmbito de determinações sociais e históricas, às quais, pelo desenvolvimento de nosso pensamento sobre a materialidade, somos capazes de pôr inquirições. Podemos não apenas compreender e explicar as determinações de nosso nascimento histórico, como ultrapassá-las, superá-las, transformá-las. Ser histórico não é ser deterministicamente constituído, programado, mas existir no interior de determinações imanentes ao processo histórico no âmbito do qual nascemos. Fontes (2009) também recorre a Marx, assinalando que se pode, com base nele, "[...] abandonar qualquer modalidade de determinismo, sobretudo o econômico, ao mesmo tempo que adquirimos as bases para compreender as determinações - históricas, objetivas e subjetivas, inclusive econômicas - da vida social contemporânea" (FONTES, 2009, p. 217).

Por concebermos, com Bhaskar (1993 apud MORAES, 2009), que o futuro é aberto, se nascemos determinados historicamente, ao longo da construção de nossa consciência do mundo e de nós mesmos, podemos alterar nossa própria consciência assim como aquelas determinações. Todavia, longe de voluntarismos, para essa empreitada é preciso conhecê-las, como alerta Gramsci:

[...] o início da elaboração crítica é a consciência daquilo que somos realmente, isto é, um 'conhece-te a ti mesmo' como produto do processo histórico até hoje desenvolvido, que deixou em ti uma afinidade de traços recebidos sem benefício no inventário. Deve se fazer, inicialmente, este inventário. (GRAMSCI, 1966, p. 12).

Essa tarefa leva-nos a indagar: de onde provêm nossas opiniões? As ideias que pensamos serem nossas, de onde saíram? O estranhamento pelo encontro com outras formas de pensar, a que se deve? Percebemos que há diferentes formas de ler, de interpretar, de entender o mundo e que as diferentes visões de mundo não são fortuitas. Vale rememorar a assertiva materialista: “[...] não é a consciência que determina a vida, mas a vida que determina a consciência" (MARX; ENGELS, 2007, p. 94). Nas palavras de Fontes (2009, p. 210), trata-se de conhecer "[...] as formas de determinação históricas, derivadas da própria existência das relações sociais que configuram a existência humana".

Poderíamos perguntar, então, quais são essas determinações históricas? Elas se traduzem nas muitas maneiras que encontramos para viver e pensar, isto é, nas relações sociais de produção que conformam nossa vida material e intelectual. $O$ mundo no qual existimos independentemente de nossas escolhas -, o modo de produção vigente - o "capitalista" -, as posições econômicas nas quais nos encontramos - relação capital e trabalho -, organiza nossa forma de viver material e intelectualmente. Contudo, é possível pensar a contrapelo. No decurso da história, sem perder sua base orgânico-natural, os homens, por meio do trabalho, autoproduziram-se, em um processo de humanização. Na síntese de Netto e Braz (2006, p. 39), "[...] o homem, é natureza historicamente transformada - mas o que é propriamente humano reside nessa transformação que situa o homem para além da natureza e o caracteriza como ser social". 
Em sua ação no mundo, o ser social encontra alternativas, pode escolher, conquanto sempre limitado pela objetividade do real. Não significa que todos os homens têm possibilidade de escolhas, pois ela não é assegurada a todos. No capitalismo, a liberdade é uma abstração e funciona como invólucro atraente que oculta relações de opressão e exploração. $O$ trabalhador "livre" dispõe e vende sua força de trabalho no mercado supostamente "livre" para o capitalista que "livremente" pode fazer a escolha de contratá-lo e dispensá-lo. Como cidadão, tem direitos e deveres, tem liberdade de ir e vir, entre tantos outros clichês que não guardam correspondência com a realidade empírica em que cada vez mais "[...] os seres sociais - em sua esmagadora maioria - são convertidos genericamente em trabalhadores, isto é, em seres cuja utilidade social fundamental é valorizar o valor e cuja necessidade singular insuperável é vender sua força de trabalho" (FONTES, 2017, p. 46).

A essência subsumida na aparência de liberdade que vivemos é a das relações entre classes sociais, cujos interesses divergentes tornam essa mesma liberdade diferente para cada uma delas. A noção de liberdade é histórica e relativa à posição que os diferentes sujeitos históricos ocupam nas relações sociais de produção. Considerando que tais relações são constituídas de dois sujeitos históricos essenciais - classe trabalhadora e burguesia -, portadores de projetos de organização social antagônicos, a liberdade está referida, de um lado, à propriedade dos meios de produção fundamentais à acumulação de capital e, de outro, à venda da força de trabalho, processo no qual a liberdade desaparece sob a necessidade existencial - somos obrigados a vender nossa força de trabalho para viver -, portanto, não há escolha.

De fato, o reino da liberdade começa onde o trabalho deixa de ser determinado por necessidade e por utilidade exteriormente imposta; por natureza, situa-se além da esfera da produção material propriamente dita. O selvagem tem de lutar com a natureza para satisfazer as necessidades, para manter e reproduzir a vida, e o mesmo tem de fazer o civilizado, sejam quais forem a forma de sociedade e o modo de produção. Acresce, desenvolve-se, o reino do imprescindível. É que aumentam as necessidades, mas, ao mesmo tempo, ampliam-se as forças produtivas para satisfazê-las. A liberdade nesse domínio só pode consistir nisto: o homem social, os produtores associados regulam racionalmente $\mathrm{o}$ intercâmbio material $\mathrm{com}$ a natureza, controlam-no coletivamente, sem deixar que ele seja a força cega que os domina; efetuam-no com o menor dispêndio de energias e nas condições mais adequadas e condignas com a natureza humana. Mas, esse esforço situar-se-á sempre no reino da necessidade. Além dele começa o desenvolvimento das forças humanas como um fim em si mesmo, o reino genuíno da liberdade, o qual só pode florescer tendo por base o reino da necessidade. E a condição fundamental desse desenvolvimento humano é a redução da jornada de trabalho. (MARX, 1971, p. 942).

Sob as relações sociais capitalistas que imperam na sociedade das mercadorias, a liberdade traveste-se de liberdade de consumo, e o conceito de classe social é destituído de seu potencial explicativo quando utilizado para estratificar grupos de indivíduos segundo a capacidade de consumo. Evidentemente essa mediação operada pelas relações sociais de produção se desdobra em formas econômicas, políticas, culturais, que atravessam nossa consciência e produzem modos de ver o mundo, perspectivas, concepções teóricas. O maior ou menor grau de compreensão dessas determinações histórico-sociais conforma não apenas nossa maneira de explicar nossa existência, como a nossa maneira de lidar com nossos temas de estudo.

Se podemos falar de nosso nascimento como ser social, histórico, o mesmo podemos falar de nossos temas de pesquisa. Eles surgem como temas na história e se transformam em objeto construído na história, em relações sociais de produção, imersos em interesses, em disputas, em projetos existenciais que nossos textos acadêmicos focam ou tangenciam, discutem 
ou negligenciam, revelam ou elidem. Podemos afirmar, então, que entre o nascimento histórico de nosso tema e sua transformação em conhecimento objetivo há um processo histórico de produção desse conhecimento. E se ele é histórico em seu nascimento, determinado pelas relações sociais de produção, nascido no âmbito do conflito entre sujeitos políticos - capital e trabalho -, é com lastro nessas determinações que o saber produzido poderá ser considerado "abordagem histórica" e não pela eventualidade de estar classificado na área de História da Educação ou outra História qualquer. Um estudo será histórico se apreender concretamente, em nível de pensamento, o real histórico.

Virginia Fontes (2009), no mesmo texto, afirma:

[...] a compreensão histórica supõe um duplo e simultâneo movimento, 'explicar' e 'compreender'. Explicar exige identificar as relações e conexões fundamentais dos fenômenos sociais, cuja objetividade se expressa na própria materialidade da organização social, isto é, na distribuição dos seres sociais em classes sociais, estabelecendo determinações efetivas, porém maleáveis. Por serem formas de organização social, podem ser mais ou menos rígidas, porém não envolvem um determinismo naturalizante, seja de cunho biológico ou psicológico. Compreender implica apreender e entranhar-se dos sentidos e significados, muitas vezes contraditórios, e mesmo antagônicos, que atravessam a experiência da vida social e plasmam sociabilidades diversas. (FONTES, 2009, p. 210).

Em A Ideologia Alemã, de 1846, Marx e Engels (1998, p. 39, grifos dos autores), afirmam que: "Os homens têm história porque têm de produzir sua vida, e têm de fazê-lo de modo determinado. [...] o primeiro ato histórico é, pois, a produção dos meios para a satisfação de suas necessidades". Sendo o trabalho atividade vital para a produção da vida, é também categoria que não pode ser negligenciada, e muito menos negada, nas análises que fazemos em nossas pesquisas. Ressaltamos que a demanda de compreendermos nossos temas de pesquisa no interior da produção da existência humana, em sua historicidade e determinações, é inexorável; se conseguirmos ver a vida pulsante e conflitiva que nossos temas possuem, quem sabe possamos explicá-lo de modo a ver neles e por eles a humanidade em nossas pesquisas.

\section{Segundo eixo: engajamento empírico na práxis da pesquisa}

Novas perguntas poderíamos colocar aqui: que sentido poderia ter a preocupação com a historicidade da pesquisa? E mais: que sentido poderia ter a preocupação com a pesquisa? Há pesquisas sem comprometimento em produzir conhecimento científico e histórico. Vemos, então, que o problema se coloca de modo mais complexo e extrapola estratégias e metodologias que podem gerar dados, informações, mas não conhecimento.

Chamemos Marx (1980, p. 16), em excerto do "Posfácio da 2a. Edição", de 1873, de $O$ Capital: "A pesquisa tem de captar detalhadamente a matéria, analisar as suas várias formas de evolução e rastrear sua conexão íntima". É impossível, por ora, extrair todas as consequências teórico-práticas dessa passagem, dada sua complexidade. Indiquemos algumas. Antes de tudo, precisamos entender o que significa matéria e como captá-la. Do ponto de vista de nosso trabalho de investigadores, matéria é tudo o que compõe nossa empiria, imediata e mediatamente. Assim sendo, matéria ou materialidade histórica é tanto nossa base empírica - documentos, entrevistas, objetos, filmes, fotografias, músicas etc. -, quanto todas as relações que permitiram sua existência - econômicas, políticas, sociais, culturais. A pesquisa, nesse caso, para resultar científica, histórica, precisa de uma base empírica consistente, de um corpus documental que será selecionado e ordenado segundo critérios do pesquisador, não podendo resultar apenas de nosso desejo, mas de hipóteses razoáveis de inquirição. A formulação, antes referida, de que "[...] toda noção ou 
conceito surge de engajamento empírico [...]" diz respeito à necessidade de um "[...] diálogo entre o conceito e a evidência, um diálogo conduzido por hipóteses sucessivas, de um lado, e a pesquisa empírica, do outro" (THOMPSON, 1981, p. 49). Faz parte do coração da pesquisa a base empírica - o fenômeno, o fato, o dado, o real -, bem como nossa capacidade de teorizar, de entendê-la conceitualmente, precisamente para compreendermos e explicarmos sua historicidade.

Nesse processo, interrogamos - obstinadamente, segundo indicação de Ianni (2011) - a materialidade, a função social do pesquisador, do intelectual da educação e de sua pesquisa na disseminação de concepções de educação e explicações, históricas ou anistóricas, acerca das questões sociais - entre as quais a Educação se coloca - que nos afligem no presente e seus projetos de futuro. A pesquisa é práxis, capta o vínculo entre prática e teoria, pensamento e ação e, como observa Minayo (2013), nada se torna intelectualmente um problema se não tiver sido, em primeiro lugar, um problema da vida prática, se não tiver inquietado o pesquisador por alguma razão em meio a tantas opções.

Se nossa tarefa como pesquisadores é apreender, compreender e explicar a materialidade de nosso tema de estudo, algumas categorias analíticas permitiriam fazer o que Marx sugere: compreender nosso tema em sua evolução histórica - gênese, constituição e transformações - no âmbito de litígios entre interesses antagônicos que caracterizam nossa sociedade. As categorias de totalidade, de contradição, de mediação, de hegemonia, de reprodução, de classe social, de relações de produção, de capital, de trabalho são ferramentas do pensar fundamentais para nos apropriarmos das "conexões íntimas" que dão sentido à nossa empiria, às relações e às correlações de forças sociais que a determinam.

Para compreendermos e explicarmos um fenômeno na área da Educação ou um objeto de pesquisa, qualquer que seja ele, é preciso considerarmos suas determinações econômicas, sociais, políticas, culturais. Dessa maneira, conseguiríamos trazer, para o campo do pensamento objetivo, a materialidade real: "[...] mediante a pesquisa, viabilizada pelo método, o pesquisador reproduz em pensamento, a essência do objeto que investiga" (NETTO, 2011, p. 6). O conhecimento teórico não é uma construção a priori; é uma apropriação pelo pensamento, pela teorização, do real existente. Por essa razão, a hipótese marxista de que é possível superar as determinações de nosso nascimento histórico põe para o pesquisador o mesmo problema: em que medida sua pesquisa possibilita o conhecimento dessas determinações naquilo que é relativo ao seu tema e necessariamente à humanidade, logo, a si próprio como ser social?

Vemos, então, que fazer pesquisa não pode ser ato mecânico de coleta e de ordenação de empiria em relato descritivo, tendo em mira um produto ou título. Saibamos ou não, estamos implicados como pesquisadores que nascemos na história e pesquisamos questões que nasceram na história. Talvez possamos dizer que muitos pesquisadores percebem metodologicamente seu trabalho de modo individual, isolado, carecendo de interlocução com a produção acumulada sobre o tema. Esquivar-se dessa interlocução fragiliza a pesquisa, impede apanhar o tema de estudo na sua materialidade, na sua concretude, nas suas condições objetivas de existência, conduzem a estratégias individualistas, competitivas e meritocráticas entre os pesquisadores que não contribuem para o avanço do conhecimento.

Para Thompson (1981), o conhecimento é cumulativo, produzido coletivamente e o é independentemente da consciência do pesquisador ao produzi-lo. No entanto, a clareza que precisamos ter sobre seu caráter coletivo, social, histórico é que o fará avançar. Assim como o trabalho e a educação, a pesquisa é atividade intencional, eminentemente coletiva. 


\section{Terceiro eixo: pesquisa em educação no Brasil hoje}

Talvez possamos pensar que muitas das dificuldades analíticas que enfrentamos, como a ausência de uma perspectiva histórica em nossos trabalhos, estejam ligadas à perspectiva de Educação na qual fomos formados e de que somos portadores. É tarefa urgente da área fazer um inventário das tendências explicativas presentes em nossa produção para desmistificar os falsos "poderes" à Educação atribuídos.

Nossa convivência harmoniosa com a ideia de que a "educação é a solução para todos os problemas", que sem ela "o aluno não adquire as competências" para a vida futura, que o "país não se desenvolverá", que os "jovens não conseguirão emprego", nos leva a fortalecer a ideia de que o professor deve responder não só pelas mazelas escolares, mas pelos graves problemas econômicos e sociais que, obviamente, fogem a sua alçada. Esse cínico argumento, pelo qual tentam atribuir a origem de problemas sociais e econômicos a uma suposta crise da aprendizagem e não à materialidade econômica, recrudesceu, na década de 1990, com o acirramento das contradições da relação capital-trabalho. Manifestou-se nas formulações ideológicas sobre capital social, empregabilidade, empoderamento ${ }^{3}$, cidadania proativa, pedagogia empreendedora, engajamento, entre tantas outras.

Esse deslocamento perverso imputa as condições materiais de existência da população brasileira a uma ideia de Educação sem qualidade, dado que é abstratamente tomada. Nessa perspectiva anistórica, os problemas sociais e econômicos são naturalizados, apartados das condições de exploração da classe trabalhadora, das negociações da burguesia interna, ao sabor dos interesses de suas várias frações, com o grande capital internacional. Prescindíveis nas explicações pragmatistas, tais problemas derivariam do fato de que os professores não têm qualidade; não se empenham na realização dos "objetivos de aprendizagem"; a gestão escolar é ineficaz; entre outras formas de responsabilizar os trabalhadores da educação, induzindo ao uso de tecnologias - novo messias na redenção educacional - e à compra de sistemas educacionais.

Resulta, desse movimento, que muitos de nós seguimos submetendo nossos alunos às avaliações em larga escala e nos submetendo a todo tipo de tarefa e intensificação do trabalho, tentando, como Marx assinalou, dar conta de nossas necessidades vitais! Nós pesquisadores não raro esquecemos das determinações da Educação, abstraímos sua história. Estando o Brasil entre as dez maiores economias do mundo, a qualidade educacional não pode se configurar como obstáculo ao desenvolvimento. Entretanto, a má qualidade do ensino emerge como racionalidade para uma explicação palatável que justifique o aumento do desemprego estrutural, da desigualdade socioeconômica, do grau de precarização em que se encontra a classe trabalhadora, cada vez mais expropriada de direitos, o que, contraditoriamente, é fonte de risco para os interesses capitalistas.

De que se trata, então? De recuperar o conceito de Educação em sentido lato, como formação humana, afastando a ideia de que sua função é adequar a força de trabalho às demandas imediatas do mercado de trabalho, produzir sujeitos individualizados afeitos à exploração do trabalho. A Educação não pode ficar colada às relações sociais dominantes, aos interesses hegemônicos. O conceito de Educação pode ser entendido, segundo Mészáros (2010), em duas direções: como vasto processo de produção de consenso burguês via mídia, aparelhos privados de hegemonia, relações de trabalho e todas as formas de construção de consciência; como educação escolarizada. Em ambas, as contradições sociais, de classe, estão presentes, coexistem e

\footnotetext{
3 Carvalho (2014, p. 181) examina o tema do "empoderamento", indicando que, quer como conceito, termo ou estratégia de intervenção, cumpre, pelo menos, quatro funções, tendo em vista produzir: 1) o ““desclassamento” da classe trabalhadora"; 2) a "mistificação ideológica"; 3) o "apassivamento da classe trabalhadora e suas organizações"; e 4) a "desresponsabilização do Estado e desoneração do capital".
} 
conflitam. Desse modo, em um mesmo movimento, articulam-se a hegemonia burguesa e a hegemonia dos subalternos.

O papel histórico da educação - escolar ou não - de produção, de reprodução e de contestação dessas relações de produção é fundamental. A Educação e a escola têm limites e possibilidades nas várias formas de pensamento, o que nos leva a concluir que não são onipotentes e que seu empoderamento é falso. O sentido da escola - em qualquer nível - é dado não apenas por sua vida interna, mas pelo conjunto de relações sociais nas quais existe e que a produz, e são históricas. Talvez fosse preciso perguntar no interior de que políticas educacionais se localizam nossos temas de estudo e no âmbito de que relações econômicas. Fora da relação entre política e economia não é possível entender qualquer processo educativo, bem como a função social da escola. Tomemos o exemplo do Pronatec (BRASIL, 2011) ${ }^{4}$ e da Reforma do Ensino Médio (BRASIL, 2017) ${ }^{5}$, ambos endereçados à formação juvenil sob o argumento de contenção da marginalidade e de preparo rápido para o trabalho simples. As duas políticas somadas a tantas outras - escondem a urgência do apassivamento da consciência crítica, da contenção de processos de erupção social que possam pôr em risco o sistema capitalista de produção.

Para Mészáros (2010, p. 45), “[...] a questão crucial, sob o domínio do capital, é assegurar que cada indivíduo adote como suas próprias as metas de reprodução objetivamente possíveis do sistema"; se é assim, nossos estudos deveriam percorrer os caminhos de sua construção, seus estratagemas de consolidação, seus slogans - "Sociedade do conhecimento", "Todos pela Educação", "Educação ao Longo da Vida", "Educação inclusiva", "Educação para alívio da pobreza", "Aprendizagem para todos", "Economia criativa", "Educação para o desenvolvimento sustentável", "Educação para a paz", "Engajamento" - para podermos entender o modo pelo qual o capital forja consensos em torno de seus propósitos. Descarta conteúdos que possam lhe oferecer riscos em razão de promoverem a desinternalização de sua concepção de mundo, na expressão de Mészáros (2010), ou a conscientização das chamadas "populações em situação de risco".

Esses elementos causticantes da realidade educacional determinam nossos temas de estudo e precisam ser trazidos à luz pelo nosso esforço de teorização. A universidade, em especial os programas de Pós-Graduação, podem realizar um importante papel no processo de orientar os pesquisadores na compreensão dos temas de pesquisa "gestados" na história, como manifestação da consciência humana na história. Se os tomarmos como passíveis de conhecimento pelo sujeito histórico, poderemos considerar que conhecê-los é conhecer a própria consciência do homem, possibilitando a articulação de outras formas de consciência.

Esta é nossa tarefa: encontrar o sentido subjacente aos nossos temas de pesquisa e construir conhecimentos que permitam o entendimento dos projetos históricos neles presentes e das perspectivas que - não raro obliteradas - estão em litígio e em disputa pelo conceito, a qual se baseia na querela do próprio mundo. É possível aceder à história, à consciência do homem e colaborar para "[...] a tarefa de romper com a lógica do capital no interesse da sobrevivência bumana [...]" (MÉSZÁROS, 2010, p. 45, grifo do autor). Certamente, a discussão proposta por Mészáros (2010) acerca da Educação é bastante complexa, mas possibilita precisamente que a

${ }^{4}$ O Programa Nacional de Acesso ao Ensino Técnico e Emprego nos Institutos Federais (Pronatec) foi aprovado pelo Congresso Nacional e transformado na Lei No 12.513, de 26 de outubro de 2011. Tem o objetivo de: i) ampliar as vagas e continuar a expansão da Rede Federal de Educação Profissional e Tecnológica; ii) fomentar a ampliação de vagas das redes estaduais de Educação Profissional; iii) incentivar a ampliação de vagas e a expansão da rede física de atendimento do Sistema S; e iv) fomentar a expansão da oferta de Educação Profissional e Técnica de nível médio na modalidade de educação a distância (BRASIL, 2011).

${ }^{5}$ A Lei $\mathbf{N}^{\mathbf{0}}$ 13.415, de 16 de fevereiro de 2017, instituiu a Política de Fomento à Implementação de Escolas de Ensino Médio em Tempo Integral (BRASIL, 2017). 
compreendamos como problemática que ultrapassa a escola, embora a contenha. Para Antunes (2012, p. 71, grifos do autor), a questão que se coloca é: "como se torna possível realizar, em termos também positivos, a tarefa histórica urgente de rumarmos para além do capital?". A resposta dada por Mészáros, citada pelo autor, é: "[...] o órgão da moral como automediação do homem em sua luta pela auto-realização é a educação" (ANTUNES, 2012, p. 71-72, grifo do autor). Importante afirmarmos que não é derivável dessa proposição a ideia de que a escola ou a Educação se revistam de caráter redentor, menos ainda "empoderado": estamos falando das contradições imanentes à Educação e à escola que, compreendidas, podem contribuir para mudanças substantivas em sua ação e para uma intervenção social revolucionária.

Mészáros (2010) chama atenção para o fato de que a transformação social, a superação da ordem do capital, demanda uma conceituação precisa no âmbito educacional, qual seja: "educação para além do capital" (MÉSZÁROS, 2010). O autor afirma que "[...] desde o início o papel da Educação é de importância vital para romper com a internalização predominante nas escolhas políticas circunscritas à 'legitimação constitucional democrática' do Estado Capitalista que defende seus próprios interesses" (MÉSZÁROS, 2010, p. 61). Concordando com essa abordagem, no que tange à pesquisa em educação no Brasil de hoje, é forçoso reconhecermos que estamos diante de um desafio gigantesco. O "céu é de chumbo", não resta dúvida, e o momento é de barbárie.

\section{À guisa de conclusão}

Quem dera que os assombramentos que hoje sofremos tivessem sido providenciados por fantasmas. Todavia, não é o caso; estamos vivendo objetivamente retrocessos econômicos, sociais, culturais e educacionais. A perda de direitos conquistados pelos trabalhadores, o congelamento de gastos pela Emenda Constitucional N ${ }^{\circ}$ 95, de 16 de dezembro de 2016 (BRASIL, 2016), a reforma trabalhista, a reforma da previdência, a carteira verde-amarela juvenil, a lei de liberdade econômica, a coerção, a violência física e simbólica, a ausência de pudor dos meios de comunicação, a parcialidade do judiciário, o descumprimento da Constituição Federal, o Congresso Nacional nas mãos de interesses privados espúrios e uma presidência da República impossível de nomear tornaram-se nossos acompanhantes diários. Essa conjuntura - de imperialismo, de inserção subordinada do Brasil nas relações internacionais, de imposição de uma lógica econômica financeirizada, de novas formas de organização dos interesses burgueses, de um movimento social que recém sai do adormecimento providenciado pelos anos Lula - evidencia que no âmbito estrutural novas formas de expropriação do trabalhador estão sendo concretizadas. Os trabalhadores enfrentam hoje grau impensável de exploração e expropriação. A escola, por sua vez, é impactada, em todos os seus níveis e modalidades, por esse movimento cruel.

No campo das políticas públicas enfrentamos recuos que haviam sido anunciados ao se suprimir, no Plano Nacional de Educação (BRASIL, 2014), a palavra "público" ligada ao financiamento da educação, à destinação de recursos públicos para as instituições públicas. $\mathrm{O}$ fenômeno da privatização da escolarização recrudesceu, particularmente na última década, em especial na Educação Superior. Para Sara Granemann (2007): 
As necessidades de a acumulação capitalista encontrar novos espaços de valorização para "resolver", ainda que momentaneamente sua crise, têm nas contrarreformas do Estado a sua expressão atual. Primeiro, pela privatização das empresas produtoras de mercadorias (no Brasil importante exemplo está na siderurgia, na produção de aço) e prestadoras de serviços (dentre outros, telefonia, água, gás, bancos); segundo, pela apropriação dos espaços até então ocupados pelas políticas sociais (previdência, saúde, educação, cultura, esportes, habitação etc.) convertidos eles mesmos em serviços-mercadoria e transmutados em negócios operados pela "iniciativa privada"; vale dizer, mercadejáveis como todas as demais mercadorias, sirvam elas ao "estômago ou à fantasia". (GRANEMANN, 2007, p. 60).

Empresários do setor privado defendem e fazem coro pela ampliação de recursos destinados às áreas sociais que se abrem como novos mercados potenciais para suas empresas. As corporações encontraram um vantajoso negócio para recuperarem lucratividade atuando no campo de serviços para o setor público e investindo em novos negócios "sociais", exemplificados pelo crescimento exponencial da oferta de matrículas em instituições privadas na modalidade da educação a distância após meados dos anos de 2000, além de aceder à punção do fundo público. Trata-se de garantir a reprodução sustentável do capital em conjunturas de crise, buscar, assim, "[...] todas as formas de valorizar o valor e operar na esfera pública, patrocinado pela mão visível do Estado" (SHIROMA, 2015, p. 16).

Esse intuito foi claramente expresso na proposição do Programa Future-se (BRASIL, 2019) às universidades. As manifestações de repúdio, os debates acalorados, indicaram que a comunidade acadêmica resistirá à entrega do patrimônio público aos fundos de investimentos e oligopólios multinacionais, à redução da universidade pública a lócus de criação de novos modelos de negócio, não aceitará a pesquisa administrada dirigida pelos interesses rentistas, hipotecando o futuro dos jovens, endividando-os desde o presente.

Como vemos, a tarefa é vasta, o momento histórico cobra-nos uma produção teórica objetiva e consistente e uma intervenção prática de natureza transformadora. Vamos ver do que somos capazes.

\section{Referências}

ANDERSON, P. O fim da História: de Hegel a Fukuyama. Rio de Janeiro: Jorge Zahar Editor, 1992.

ANTUNES, C. Educação em Mészáros: trabalho, alienação e emancipação. Campinas: Autores Associados, 2012.

BRASIL. Emenda Constitucional $\mathrm{n}^{\circ}$ 95, de 15 de dezembro de 2016. Altera o Ato das Disposições Constitucionais Transitórias, para instituir o Novo Regime Fiscal, e dá outras providências. Diário Oficial da União: seção 1, Brasília, DF, n. 241, p. 2-3, 16 dez. 2016.

BRASIL. Lei $\mathrm{n}^{\circ}$ 12.513, de 26 de outubro de 2011. Institui o Programa Nacional de Acesso ao Ensino Técnico e Emprego (Pronatec); altera as Leis n⿳․ 7.998, de 11 de janeiro de 1990, que regula o Programa do Seguro-Desemprego, o Abono Salarial e institui o Fundo de Amparo ao Trabalhador (FAT) [...]. Diário Oficial da União: seção 1, Brasília, DF, n. 207, p. 1-3, 27 out. 2011.

BRASIL. Lei no 13.005, de 25 de junho de 2014. Aprova o Plano Nacional de Educação - PNE e dá outras providências. Diário Oficial da União: seção 1, Brasília, DF, n. 120-A, edição extra, p. 1-7, 26 jun. 2014. 
BRASIL. Lei $\mathrm{n}^{\circ}$ 13.415, de 16 de fevereiro de 2017. Altera as Leis $\mathrm{n}^{\text {os }} 9.394$, de 20 de dezembro de 1996, que estabelece as diretrizes e bases da educação nacional, e 11.494, de 20 de junho 2007, que regulamenta o Fundo de Manutenção e Desenvolvimento da Educação Básica e de Valorização dos Profissionais da Educação, a Consolidação das Leis do Trabalho - CLT, [...]; revoga a Lei no 11.161, de 5 de agosto de 2005; e institui a Política de Fomento à Implementação de Escolas de Ensino Médio em Tempo Integral. Diário Oficial da União: seção 1, Brasília, DF, n. 35, p. 1-3, 17 fev. 2017.

BRASIL. Lei $\mathbf{n}^{\mathbf{0}}$, de de de 2019. Institui o Programa Institutos e Universidades Empreendedoras e Inovadoras - FUTURE-SE, e dá outras providências. 2019. Disponível em: <http://apub.org.br/wp-content/uploads/2019/10/FUTURE-SE-vfinal1.pdf>. Acesso em: 3 nov. 2019.

CARVALHO, I. O fetiche do empoderamento: do conceito ideológico ao projeto econômicopolítico. In. MONTAÑO, C. (Org.). O canto da sereia: crítica à ideologia e aos projetos do terceiro setor. São Paulo: Cortez, 2014. p. 144-184.

DUAYER, M. Capital: a verdade absoluta do ceticismo pós-moderno e adjacências. In: OLIVEIRA, I. F. de. et al. (Org.). Marx hoje: pesquisa e transformação social. São Paulo: Outras Expressões, 2016. p. 137-154.

EAGLETON, T. Ideologia: uma introdução. São Paulo: UNESP; Boitempo, 1997.

FONTES, V. Capitalismo em tempos de uberização: do emprego ao trabalho. Marx e o Marxismo, Niterói, v. 5, n. 8, p. 45-67, jan./jun. 2017.

FONTES, V. Determinação, história e materialidade. Trabalho, Educação e Saúde, Rio de Janeiro, v. 7, n. 2, p. 209-229, jul./out. 2009. DOI: https://doi.org/10.1590/s1981$\underline{77462009000200002}$

FUKUYAMA, F. O fim da história e o último homem. Rio de Janeiro: Rocco, 1992.

GALEANO, E. O livro dos abraços. 9. ed. Porto Alegre: LPM, 2002.

GRAMSCI, A. Concepção dialética da História. Rio de Janeiro: Civilização Brasileira, 1966.

GRANEMANN, S. Políticas sociais e financeirização dos direitos do trabalho. Em Pauta, Rio de Janeiro, n. 20, p. 56-68, 2007.

HARVEY, D. A condição pós-moderna. São Paulo: Edições Loyola, 1992.

IANNI, O. A construção da categoria. HISTEDBR On-line, Campinas, número especial, v. 11, n. 41, p. 397-416, abr. 2011. DOI: https://doi.org/10.20396/rho.v11i41e.8639917

IASI, M. Política, Estado e ideologia na trama conjuntural. São Paulo: ICP, 2017.

MARX, K. O capital: crítica da economia política. Tradução de Reginaldo Sant'Anna. Rio de Janeiro: Civilização Brasileira, 1971. (Livro III, volume VI).

MARX, K. Manuscritos econômico-filosóficos e outros textos escolhidos. 2. ed. São Paulo: Abril Cultural, 1978. (Os pensadores).

MARX, K. O capital: crítica da economia política. Posfácio da 2. ed. São Paulo: Civilização Brasileira, 1980. (Volume 1).

MARX, K.; ENGELS, F. A ideologia alemã. São Paulo: Martins Fontes, 1998. 
MARX, K.; ENGELS, F. A ideologia alemã: crítica da mais recente filosofia alemã em seus representantes Feuerbach, B. Bauer e Stirner, e do socialismo alemão em seus diferentes profetas (1845-1846). São Paulo: Boitempo Editorial, 2007.

MÉSZÁROS, I. A educação para além do capital. São Paulo: Boitempo, 2010.

MINAYO, M. C. de S. (Org.). Pesquisa social: teoria, método e criatividade. 33. ed. Petrópolis: Vozes, 2013.

MONTAÑO, C. O canto da sereia: crítica à ideologia e aos projetos do "terceiro setor". São Paulo: Cortez, 2014.

MORAES, M. C. M. "A teoria tem consequências": indagações sobre o conhecimento no campo da educação". Educação \& Sociedade, Campinas, v. 30, n. 107, p. 585-607, maio/ago. 2009. DOI: https://doi.org/10.1590/s0101-73302009000200014

MORAES, M. C. M. O renovado conservadorismo da agenda pós-moderna. Cadernos de Pesquisa, v. 34, n. 122, p. 337-357, maio/ago. 2004. DOI: https://doi.org/10.1590/s010015742004000200004

NETTO, J. P. Introdução ao estudo do método de Marx. São Paulo: Expressão Popular, 2011.

NETTO, J. P. O materialismo histórico como instrumento de análise das políticas sociais. In: NOGUEIRA, F. M. G.; RIZOTTO, M. L. F. (Orgs.). Estado e políticas sociais. Cascavel: Edunioeste, 2003. p. 11-28.

NETTTO, J. P.; BRAZ, M. Economia política: uma introdução. São Paulo: Cortez, 2006.

SHIROMA, E. O. O Estado como cliente: interesses empresariais na coprodução da inspeção escolar. Trabalho Necessário, Rio de Janeiro. v. 13, n. 22, p. 57-79, 2015. DOI: https://doi.org/10.22409/tn.13i22.p9594

THOMPSON, E. P. A miséria da teoria. Rio de Janeiro: Zahar, 1981.

VALENTINI, S. Do liberal ao pós-moderno: o debate sobre as ações afirmativas na produção acadêmica da área da educação (2012-2016). 2018. 168 f. Dissertação (Mestrado em Educação) Universidade do Estado de Santa Catarina, Florianópolis, 2018.

WOOD, E. M. Em defesa da história: o marxismo e a agenda pós-moderna. Crítica Marxista, Campinas, n. 3, p. 118-128, 1996.

Recebido em 03/09/2019

Aceito em 30/10/2019

Publicado online em 10/11/2019

\footnotetext{
Olinda Evangelista

Professora Sênior no Programa de Pós-Graduação em Educação da Universidade do Oeste Catarinense (UNOESC). Professora Voluntária na Universidade Federal de Santa Catarina. Bolsista de Produtividade em Pesquisa do CNPq.

\section{Eneida Shiroma}

Professora Titular na Universidade Federal de Santa Catarina, Bolsista de Produtividade em Pesquisa CNPq e vice-líder do Grupo de Estudos sobre Política Educacional e Trabalho (GEPETO).
} 